\title{
$\nabla$ Blood Lactate Levels and Hematological Parameters in Medical Students before and after Half Marathon
}

\section{IJCRR}

Section: Healthcare

ISI Impact Factor

(2019-20): 1.628

IC Value (2019): 90.81

$\operatorname{SJIF}(2020)=7.893$

(c) (7) (8)

Copyright@IJCRR

\section{Indira Ashok Hundekari ${ }^{1}$, Nisha Gupta ${ }^{2}$, Nilima N. Dongre ${ }^{1}$}

'Associate Professor, Department of Biochemistry, BLDE (DU) Shri B.M. Patil Medical College Hospital and Research Centre, Vijayapur;

Karnataka 586103, India; ${ }^{2}$ MBBS Phase 111, BLDE (DU) Shri B.M. Patil Medical College Hospital and Research Centre, Vijayapur Karnataka 586103 , India.

\section{ABSTRACT}

Background: Prolonged and intense physical exercise causes multiple significant changes in the body. These changes can lead to health disorders and deterioration of physical fitness.

Objective: Marathon runners require medical attention and the performance of laboratory assays. Hence we planned to study blood lactate and haematological parameters in young healthy subjects before and after the marathon

Methods: The study group comprises 19 healthy medical students aged between 20-25 years who are amateur nonprofessional runners. Blood lactate level, Anthropometric parameters and haematological parameters were estimated before and after the half marathon, using standard assay procedures.

Results: We found a significant increase $(P<0.001)$ in blood lactate level after the marathon as compared to before the marathon. We also confirmed leukocytosis after the half marathon and decreased percentages of lymphocytes and eosinophils; while the percentage of monocytes, haemoglobin concentration, $\mathrm{HCT}, \mathrm{RBC}, \mathrm{MCH}, \mathrm{MCV}$, and MCVC after the marathon remained unchanged.

Conclusion: Marathon running is a prolonged and intense physical effort that leads to several changes in the organism, as demonstrated by the results of haematological parameters and blood lactate analysis. The growing popularity of long-distance running, especially among amateurs, indicates the importance of biochemical investigations during such activity.

Key Words: Half marathon, Blood lactate, Leukocytosis, Haematological parameters, Amateur, Nonprofessional runners

\section{INTRODUCTION}

Physical inactivity is considered to be one of the main causes of primary hypertension, independently of weight status. Physical activity levels are becoming lower among children and adolescents worldwide, demonstrating that new generations are more sedentary than the previous ones. This raises concerns about which strategies could help children and adolescents to increase their physical activity levels, as physical activity in childhood has been demonstrated to be an effective intervention to combat obesity and hypertension in adult life. $^{1}$

In recent years, the practice of marathons has become very popular. Moreover, much attention has been drawn to the promotion of physical exercise to prevent diseases. ${ }^{2}$ The marathon is a long-distance running race with an official distance of $42.95 \mathrm{~km}$ usually run as a road race. It is one of the original modern Olympic events in 1896. Each year the world witnesses more than 800 marathon events with a vast variety of participants. The half marathon is a road running event of $21.0975 \mathrm{~km}$ (half the distance of a marathon). It is not a part of the world championships or Olympic programs. But the event gained its championships in 1992 in the form of the IAAF world half marathon championships. Its popularity has kept growing \& it is now one of the most popular road events. ${ }^{3}$

The blood lactate level has been used as an indicator of the ability to perform endurance exercise in clinical practice. ${ }^{4}$ Hematological disturbances after exercise, such as haemolysis and/or iron deficiency are well documented ${ }^{5}$ but of little concern from a health perspective. Prolonged and intense physical exercise causes multiple significant changes in the body. These changes can lead to health disorders and dete-

\section{Corresponding Author:}

Dr. Indira Hundekari, Associate Professor, Department of Biochemistry, BLDE (DU) Shri B.M. Patil Medical College Hospital and Research Centre, Vijayapura; Karnataka 586103, India; E-mail: indira_hundekari@yahoo.com

ISSN: 2231-2196 (Print)

Received: 02.10 .2020
ISSN: 0975-5241 (Online)

Revised: 08.12 .2020
Accepted: 12.01 .2021
Published: 19.05 .2021 
rioration of physical fitness. ${ }^{6}$ Participants in marathon races may require medical attention and the performance of laboratory assays. Hence we planned to study blood lactate \& physiological parameters before and after the half marathon in young healthy medical students from BLDE (Deemed to be University), Shri B M Patil Medical College Hospital and Research Centre, Vijayapur.

\section{MATERIALS AND METHODS}

The present study was carried out in the Department of Biochemistry, BLDE (Deemed to be University) Shri B. M. Patil Medical College, Hospital and Research Centre, Vijayapur. A random selection method was used for the selection of 30 subjects from our University. Before the study, informed consent was obtained from the students and the experimental procedures were reviewed and approved by the BLDE (Deemed to be University) Human Research Ethical Committee [IEC letter no. BLDE (DU)/IEC/27/2017-18].

Selection of the subjects: Medical students from our University who are healthy volunteered and involved in various sports, athletes, non-smokers, non-alcoholics and not on medications for any acute or chronic illness were included in this study. We invited medical students from our University who are amateur nonprofessional, male runners. Of 30 subjects recruited, 24 runners agreed to take part in our study. First, the subjects underwent a health examination to check their health and to reject unfit individuals. They received a talk beforehand in which the study was explained to them, and once they understood they gave consent for the study. None of the participants experienced an adverse medical event during or after the race as they were doing exercise for at least 30 minutes of moderate-intensity physical activity for 5 or more days a week.

At baseline, the study participants were asked to complete a standardized questionnaire to gather information on physical characteristics such as exercise during the last year and personal information such as eating habits, allergy, medication for any illness etc. The anthropological measurements were made before the marathon and biochemical parameters were assessed before and after the half marathon in the study group. The subjects were instructed to refrain from intense physical activity at least 24 hours before the marathon. All participants submitted a written consent form.

After a night's rest, they ate a light breakfast or a fruit of their choice at 7:00 am. During the run, the runners nourished themselves with prepared food and drinks served at a special stand. $5 \mathrm{ml}$ venous blood samples were collected from the subjects under aseptic conditions, before starting the half marathon and after the marathon. The serum was separated by centrifugation at 3,000 rpm for 10 minutes, at room temperature. Then all samples were immediately placed at $4^{\circ} \mathrm{C}$ until they were processed, to get accurate and reproducible results.

1. Blood Lactate by colourimetric method (VITROS LAC slide method) using VITROX chemistry products LAC slides - Commercial kit.

2. EDTA-blood, to determine haematological parameters by automated cell counter analyzer; SysmaxKx- 21

\section{Statistical analysis}

All the data collected has been analyzed and expressed as mean \pm SD. The statistical analysis of data was done by student's ' $t$ ' test and Pearson's correlation test using SPSS latest version. $\mathrm{P}<0.05$ is considered statistically significant. Correlation of body fat percentage and blood lactate level before and after half marathon was analyzed with Pearson's correlation test.

\section{RESULTS AND DISCUSSION}

Out of twenty-four runners, nineteen runners completed the race. However, five runners did not finish the race and were therefore excluded from the study analysis. Ages of all the participants were ranged from 19 to 24 years with anthropometric parameters as shown in Table 1. All the participants were normotensive.

Participation in long-distance running events has grown significantly in the last decade. The completion time for professionals is less than 2 hrs 30 minutes $^{7}$ while in our study group completion time ranged between $3 \mathrm{~h} 10$ minutes to 3 h 40 minutes. Christine Bekos et al. reported that the time required for a half marathon was $117.0 \pm 2.8$ minutes. $^{8}$

Heart rate is an important variable to determine physical exercise intensity. We observed a significant increase $(\mathrm{P}<0.001)$ in the heart rate of all the participants at the end of the half marathon. An increase in heart rate $(65 \%$ of maximal frequency) was obtained by Diamond et al. ${ }^{9}$ while Halliwell et al. reported an increase in heart rate to at least $79 \%$ of its maximal value after high-intensity exercise. ${ }^{10}$ Several investigators have shown that endurance-trained athletes have faster heart rate responses after the cessation of exercise as compared with sedentary subjects. ${ }^{11}$

We found a significant increase $(\mathrm{P}<0.05)$ in blood lactate level after the marathon as compared to before the marathon (Table 2 ); this is because, during exercise, muscles produce lactate rapidly, whereas lactate clearance is slowed. Ferri et al. suggested that highly-trained athletes can produce and tolerate higher lactate concentrations during incremental exercise until exhaustion. ${ }^{12}$ A positive correlation $\left(\mathrm{R}^{2}=0.013\right)$ was observed in the body fat percentage of participants with blood lactate before the marathon (Figure 1) and $\left(\mathrm{R}^{2}=0.002\right)$ with blood lactate after the marathon (Figure 2). The individuals who had high body fat percentage showed high lactate level. 
Daniels et al. suggested that the lactate threshold level is an excellent indicator for predicting endurance capacity. As the blood lactate level has been used as an indicator of the ability to perform endurance exercise in clinical practice and also, during high-intensity exercise, lactate production is higher than its removal from the body. ${ }^{13}$ Further he supported that the individuals with a high lactate level have delayed onset of muscle fatigue and can exercise for a long duration and at high intensity. Additionally, those with a high fitness level have high lactate level. ${ }^{14}$

Our findings confirm leukocytosis after the half marathon and decreased percentages of lymphocytes and eosinophils, while the percentage of monocytes was unchanged (Table 3 ). It is generally assumed that leukocytosis after a race is mainly caused by demargination of WBCs induced by increased blood flow; however, Traiperm et al. reported increased absolute numbers of neutrophils and leukocytosis observed in runners might be due to the inflammatory response caused by tissue injury. ${ }^{15}$ We observed no statistically significant differences in haemoglobin concentration, $\mathrm{HCT}, \mathrm{RBC}, \mathrm{MCH}$, $\mathrm{MCV}, \mathrm{MCVC}$ after the marathon which is inconsistent with Zbigniew Jastrzębski et al. ${ }^{16}$ The limitation of the study is the low number of participants analyzed, which limits the generalization of the results obtained in the present research.

\section{CONCLUSION}

Participation in long-distance running events has grown significantly in the last decade and is becoming more popular. Marathon running is a long and very intensive exercise that shows alterations in blood lactate and the haematological profile. The performance of a prolonged endurance event is associated with several potential biochemical changes, of which athletes and doctors need to be aware and play an important role in sports diagnostics by indicating the deployment of leukocytes to sites of injury and important for monitoring the effect of training on individuals those participate in sports. It would help to define the norm and identify the possible health consequences. Physical activity has a very beneficial effect on both people's physical condition and the quality of their lives.

\section{ACKNOWLEDGEMENT}

We are grateful to BLDE Deemed to be University, Shri B M Patil Medical College Hospital and Research Centre for funding the BLDE (DU) STS research project. We express our gratitude to all the participants who consented to volunteer in the project. The authors acknowledge the immense help received from Mr. Rajan K. (2017-18 Batch) for organizing the event; we also acknowledge Mr Naregal and Mrs Jayashree for technical assistance. The authors acknowledge the immense help received from the scholars whose articles are cited and included in references of this manuscript. The authors are also grateful to authors/editors/publishers of all those articles, journals and books from where the literature for this article has been reviewed and discussed.

\section{Conflict of Interest: Nil}

Source of funding- This student research project is funded by BLDE Deemed to be University, Shri B. M. Patil Medical College, Hospital and Research Centre, Vijayapur.

\section{Authors' Contribution:}

1. Dr. Indira Hundekari -Framed the Research Question and planned the project, analyzed the results and prepared the manuscript.

2. Nisha Gupta - MBBS Phase III - Received fund from BLDE Deemed to be University, Organized the event, Played important role in collection of data and participants informed consent.

\section{Dr. Nilima Dongre- Assisted in Statistical analysis.}

\section{REFERENCES}

1. Siegrist M, Lammel C, Haller B, Christle J, Halle M. Effects of a physical education program on physical activity, fitness, and health in children: The Juven TUM Project. Scand J Med Sci Sports 2013;23:323-330.

2. Jastrzebski Z, Radziminski MZL, Konieczna A, Kortas J. Damage to liver and skeletal muscles in marathon runners during a $100 \mathrm{~km}$ run with regard to age and running speed. J Human Kinetics 2015;45:93-102.

3. IAAF competition rules for road races. Int Assoc Athletics Federations. 2009.

4. Svedahl K, MacIntosh BR. Anaerobic threshold: the concept and methods of measurement. Can J Appl Physiol 2003;28(2):299323.

5. Gledhill N, Warburton D, Jamnik V. Haemoglobin, blood volume, cardiac function, and aerobic power. Can J Appl Physiol 1999;24:54-65.

6. Kamińska J, Podgórski T, Pawlak M. Variability of selected hematological and biochemical markers in marathon runners. Trends Sport Sci 2015;3(22):125-132.

7. Orquín-Ortega E, Vega-Ruiz V, García AR, López-Araque B. Biochemical changes in popular runners after a marathon (Stress Test). Arch Med Deporte 2016;33(5):306-311.

8. Bekos C, Zimmermann M, Unger L, Janik S, Hacker P, Mitterbauer A, et al. Non-professional marathon running: RAGE axis and ST2 family changes concerning open-window effect, inflammation and renal function. Sci Rep 2016;6(1):32315.

9. Diamond TH, Smith R, Goldman AP, Myburgh DP. Holter Monitoring and marathon running. Reproduced by Sabinet Gateway under license granted by the publisher dated 2012:14-15.

10. Halliwell JR, Taylor JA, Hartwig TD, Eckberg DL. Augmented baroreflex heart rate gain after moderate-intensity, dynamic exercise. Am J Physiol 1996;270:R420- R426.

11. Rossow L, Yan H, Fahs CA, Ranadive SM, Agiovlasitis S, Wilund KR, et al. Post-exercise hypotension in an endurancetrained population of men and women following the high-inten- 
sity interval and steady-state cycling. Am J Hypertens 2010;23: 358-367.

12. Ferri A, Adamo S, La Torre A, Marzorati M, Bishop DJ, Miserocchi G. Determinants of performance in 1,500-m runners. Eur J Appl Physiol 2012;112:3033-3043.

13. Daniels SR. International differences in secular trends in childhood blood pressure: a puzzle to be solved. Circulation 2011;124:378-380.
14. Power SK, Howley ET. Exercise Physiology: Theory and application to fitness and performance, 9th Edition, Baltimore, MD: Lippincott Williams \& Wilkins. 2014.

15. Traiperm N, Gatterer H, Burtscher M. Plasma electrolyte and haematological changes after marathon running in adolescents. Med Sci Sports Exerc 2013;45(6):1182-7.

16. Jastrzebski1 Z. A 100-Km Run In Relation Runners. Int J Occup Med Envt Health 2016;29(5):801-814.

Table 1: Anthropometric parameters and physiological variables in the study group (n=19)

\begin{tabular}{lll} 
SI No & Parameters & Mean \pm SD $($ Range $)$ \\
1 & Age ( Years) & $21.5 \pm 1.63(19-24)$ \\
2 & Height $(\mathrm{Cm})$ & $173.37 \pm 4.95(160-183)$ \\
3 & Weight $(\mathrm{Kg})$ & $68.81 \pm 9.32(55-92)$ \\
4 & Waist Circumference $(\mathrm{Cm})$ & $84 \pm 3.41(79-94)$ \\
5 & Hip Circumference $(\mathrm{Cm})$ & $92.87 \pm 3.70(86-103)$ \\
6 & W/H ratio & $0.90 \pm 0.018(0.85-0.93)$ \\
7 & BMI $\left(\right.$ Kg $\left./ \mathrm{m}^{2}\right)$ & $22.69 \pm 2.12(20.9-27.8)$ \\
8 & Body fat percentage & $15.97 \pm 2.70(13.48-22.45)$ \\
\hline
\end{tabular}

Table 2: Heart rate, BP, and blood lactate levels before and after the marathon in the study group (n=19)

\begin{tabular}{llccc} 
S1 No. & Parameters & Before Half Marathon & After Half Marathon & P-value \\
1 & Heart rate (beats/min) & $75.12 \pm 3.34$ & $91.12 \pm 5.45$ & $<0.0001^{* * *}$ \\
& & $(68-80)$ & $(84-105)$ & \\
2 & Systolic BP & $121.25 \pm 3.99$ & $138.94 \pm 5.86$ & $<0.0001 * * *$ \\
& $($ mmHg) & $(116-130)$ & $(126-148)$ & \\
3 & Diastolic BP & $83.19 \pm 4.83$ & $90.5 \pm 4.98$ & $0.0002 * * *$ \\
& $($ mmHg) & $(78-92)$ & $(82-98)$ & \\
4 & Blood lactate $(\mathrm{mmol} / \mathrm{L})$ & $3.85 \pm 1.06$ & $4.9 \pm 0.87$ & $0.005^{* *}$ \\
\hline
\end{tabular}

Values without parenthesis indicate Mean $\pm \mathrm{SD}$ values and those in parenthesis are range of values of the study group. ${ }^{*} \mathrm{P}<0.05$, ${ }^{* *} \mathrm{P}<0.01$ and ${ }^{* * *} \mathrm{P}<0.001$

Table 3: Shows Mean \pm SD levels of haematological parameters before and after the marathon in the study $\operatorname{group}(n=19)$

$\begin{array}{llccc}\text { SI No. } & \text { Parameters } & \text { Before Half Marathon } & \text { After Half Marathon } & \text { P value } \\ 1 & \text { Total count }(\mathrm{TC})(\text { cells/cmm }) & 6630 \pm 1149.39 & 7995 \pm 1777.46 & 0^{*} \\ & & (5050-9180) & (5290-11250) & \\ 2 & \text { Neutrophils (\%) } & 52.49 \pm 7.31 & 63.83 \pm 8.35 & 0.0003^{*} \\ & & (33.3-65.3) & (49.1-80.7) & \\ 3 & \text { Lymphocytes (\%) } & 39.65 \pm 6.86 & 33.27 \pm 11.93 & 0.07 \text { NQS } \\ & & (29.2-57.4) & (15.9-70.2) & 0.0212^{*} \\ 4 & \text { Eosinophils (\%) } & 3.08 \pm 1.38 & 2.04 \pm 1.02 & \\ & & (1.4-6.3) & (0.3-4.3) & 0.979 \text { NS }\end{array}$


Table 3: (Continued)

\begin{tabular}{llccc} 
S1 No. & Parameters & Before Half Marathon & After Half Marathon & P value \\
\hline 6 & Basophils (\%) & $0.77 \pm 0.39$ & $0.46 \pm 0.26$ & 0.01 * $^{*}$ \\
& & $(0.3-1.7)$ & $(0.2-1.2)$ & \\
7 & Red Blood Cell Counts (RBC) (mil- & $5.26 \pm 0.26$ & $4.96 \pm 1.16$ & 0.32 NS \\
& lions/cmm) & $(4.87-5.74)$ & $(0.71-5.94)$ & \\
8 & Hb (gm \%) & $15.52 \pm 0.81$ & $15.52 \pm 0.84$ & 0.983 NS \\
& & $(14.3-17.1)$ & $(14.3-17.5)$ & \\
\hline
\end{tabular}

Figures without parenthesis indicate Mean $\pm \mathrm{SD}$ values and those in parenthesis are range of values of the study group. ${ }^{*} \mathrm{P}<0.05$ and NS- indicates not significant

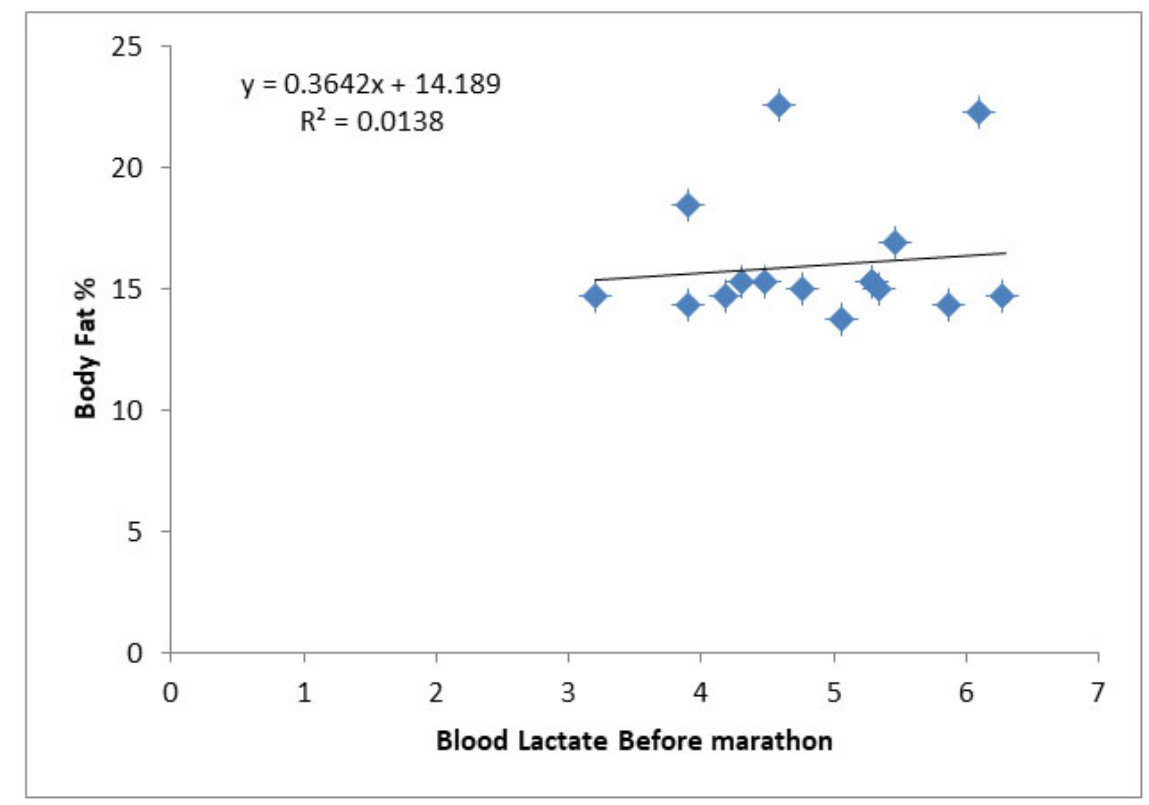

Figure 1: Correlation of body fat percentage with blood lactate levels before marathon in study group.

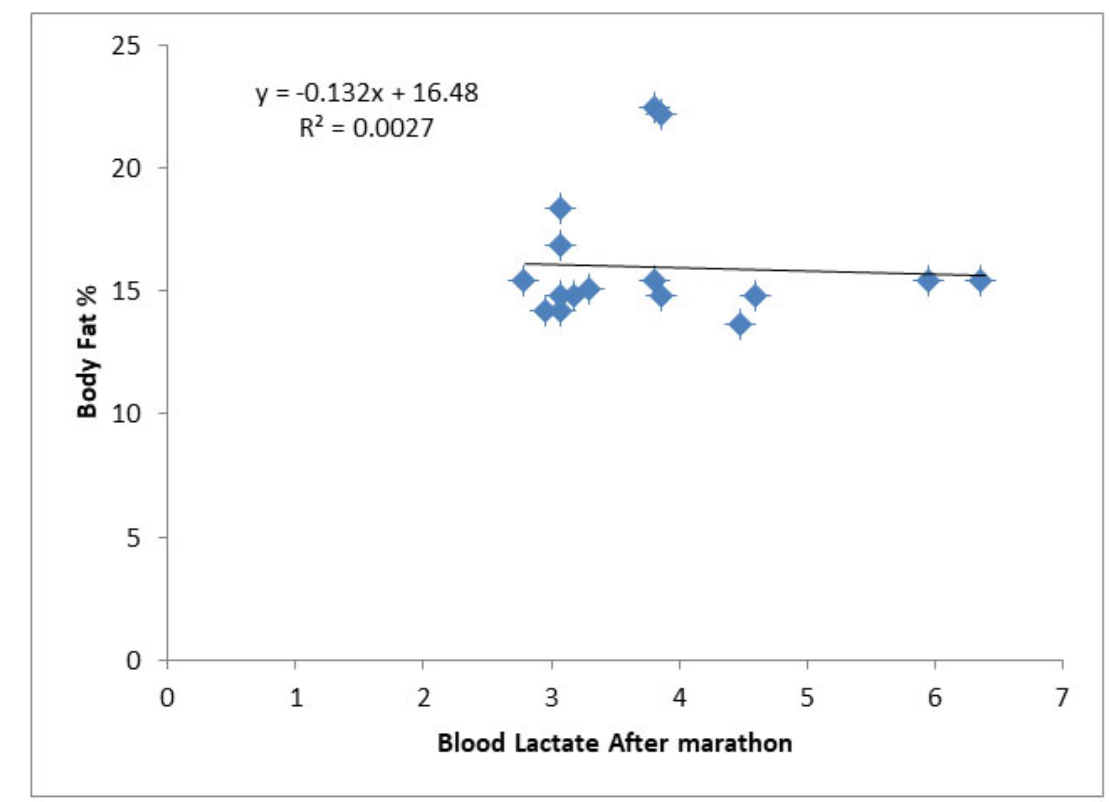

Figure 2: Correlation of body fat percentage with blood lactate levels after marathon in study group. 